\title{
The Immuno-Pathology of the Human Placenta
}

\section{P D Gupta and Alpana Gupta}

${ }^{1}$ Former Director Grade Scientist, Centre for Cellular and Molecular Biology, Hyderabad, India.

${ }^{2}$ R\&D Project Leader, Boehriger Ingelhiem Pharmaceuticals, Inc. Ridgefield, CT, USA

*Corresponding Author: P D Gupta, 1Former Director Grade Scientist, Centre for Cellular and Molecular Biology, Hyderabad, India

Received date: January 24, 2021 Accepted date: February 18, 2021 Published date: March 02,2021

Citation: P D Gupta and Gupta A. (2021) The Immuno-Pathology of the Human Placenta. J of Obstetrics Gynecology and Reproductive Science. 5(2); DOI: $10.31579 / 2578-8965 / 0060$

Copyright: (C) 2021, P D Gupta, This is an open access article distributed under the Creative Commons Attribution License, which permits unrestricted use, distribution, and reproduction in any medium, provided the original work is properly cited.

\begin{abstract}
The human placenta once was thrown after the delivery, found to be a very useful organ though it has very short life. With more and new research the old concept about placenta has changed. Now it is well established that health of growing embryo depends on the health of the placenta. To begin with immunology of neonate also depends on transplacental transport. It is well established that the health of the growing embryo depends on the health of the transplacental transport. Normally, IgG can be transported through placenta however, in Covid-19 infected pregnant woman even $\operatorname{IgM}$, which is much bigger molecule than $\mathrm{IgG}$, can also be transported and are found in the embryo.
\end{abstract}

Keywords: Immuno-Pathology; Human Placenta; IgG

\section{Introduction}

Placenta is a temporary organ that develops in the uterus only during pregnancy. It is simple in structure but most active, multifunctional; performs many physiological functions for the developing embryo some of the very important functions for the mother during pregnancy. The complex interplay of processes and cells involved in healthy pregnancy is still controversial and poorly understood. The placenta is formed by cells that originate from the foetus and is therefore the first of the foetal organs to develop [1].

Immunity during pregnancy is modulated through placenta; however, there is no consensus regarding the existence of a placental microbiome in healthy full-term pregnancies. Recently, Sterpu et al. [1]. Found no evidence to support the existence of a placental microbiome in the study of 76 term pregnancies, which used polymerase chain reaction (PCR) amplification and sequencing techniques and bacterial culture experiments. However, Researchers have found a surplus of pathogenic bacteria in placentas from premature births. Researchers who have found evidence for the presence of bacteria detected only low levels of microbial DNA, or cultured a few specimens in the lab. It's still unclear whether the bacteria are alive within the womb (Fig.1). Nevertheless Aagaard [3, 4]. argued that even a few microbes might boost a developing foetus' immune system.

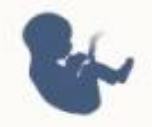

In Utero

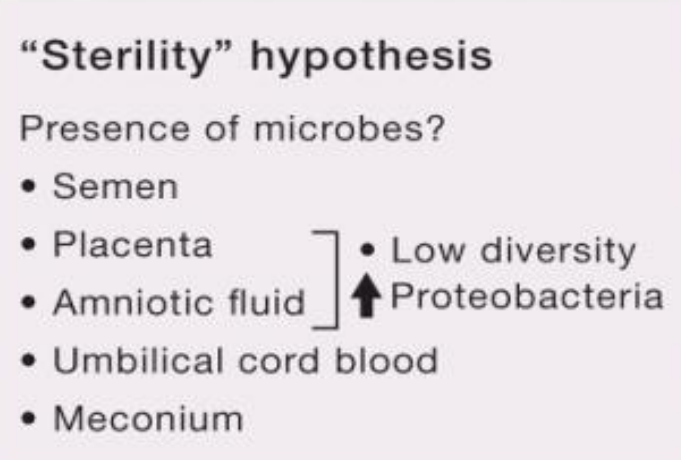

Figure 1. According to Sterility Hypothesis intra uterine environment is in general "sterile" 
Successful placental development is crucial for optimal growth, development, maturation, and survival of the embryo/foetus into adulthood [1]. However, many epidemiologic and experimental studies demonstrate the profound influence of intrauterine environment (including microbiota) on foetal life [5]. The debate on where a baby meets microbes for the first time isn't yet settled but all circumstantial evidence points towards that the foetus is primed in the womb. A human's genes are laid down at conception however, recently, it was realized that genes haven't a fixed, predetermined program, they are also regulated by epigenetic factors; among those macrobiotics consider as an important candidate [6].

\section{Transplacental transmission}

Placenta acts as a blood-placental barrier (BPB) between mother and foetus, but it is the "leakiest" barrier and is a very poor block for chemicals. It is composed of several layers of cells acting as a barrier for the passive diffusion of substances between the maternal and foetal circulatory systems. Bacterial or viral infection of the mother during the course of pregnancy can cross the placenta and actively infect the foetus. However, especially for bacteria, it is more common for mothers to experience an infection that can be treated without overt foetal infection. The infection may result in abortion or stillbirth. Young et al. [7]. studied the microbiota of human and mouse dyads to understand relationships between microbiota and developing foetus, localize bacteria in the foetus, and demonstrate bacterial viability. The placenta cannot screen out all harmful substances: a rubella [8] outbreak resulted in a sudden increase of babies being born blind, and the sudden increase of deformed limbs due to the use of thalidomide [9]. The birth process influences a first major microbial colonization; factors related to the labour and birth environment have been shown to influence the initial colonization process of the newborn microbiota [10-12]. Studies have shown that there are distinct differences in the microbiota profiles of new-borns born vaginally compared to those born by caesarean. Babies born vaginally also receive an early dose of good bacteria as they travel through their mother's birth canal, which may boost their immune systems and protect their intestinal tracts [1]

\section{Foetal Immunology}

A developing foetus is constantly exposed to foreign proteins and cells, which are transferred from the mother through the placenta. In humans, this exposure is more extensive than in many other mammals [14].Therefore, foetuses are also acquiring a functioning immune system - one that can recognize foreign proteins, but is less inclined than a mature immune system to go on the attack $[15,16]$.Through recent researches it is established that the foetal immune system is more active [17].

\section{Placental Pathology}

The placenta begins to develop upon implantation of the blastocyst into the endometrium [1].Problems with the placenta are frequently found to be the cause of miscarriage or stillbirth, especially early miscarriage [18].Clinically the abnormality presents with vaginal bleeding, in the second or third trimester or during labour, due to an associated placenta previa [19].Abnormal formation of the placenta has also been linked with two of the most common pregnancy disorders - pre-eclampsia [20].which causes a set of symptoms including high blood pressure in the mother, and foetal growth restriction, where the baby fails to reach its genetically determined growth potential; both can result in stillbirth and are associated with poor health in later life The most common cause is a problem in the placenta (the tissue that carries food and blood to the baby).Usually, the placenta positions itself at either the top or side of the uterus and can behaving anterior placenta and if attaches to the back of the uterus, near the spine, known as a posterior placenta. Sometimes the placenta does not grow properly and can attach very low down may block the cervical opening (praevia) can also grows too deeply into the wall of the uterus (accrete) [21].

Potentially heavy vaginal bleeding during pregnancy can be due to, placental problems include placental abruption, praevia, accrete..Placental abruption results from premature separation of the placenta from the uterus, before the onset of labour. A rare placental abnormality where either all (diffuse placenta membranacea) or part (partial placenta membranacea) is covered by chorionic villi (placental cotyledons). [22].Birth defects and genetic disorders can cause Intra uterine growth restriction (IUGR). Babies who are born to the mothers who are either infected or having high blood pressure, also the mothers who smokes, or drinks too much alcohol or drug edicts, will have IUGR.

The uteroplacental vascular insufficiency can occur if the placenta does not develop properly, or developed properly but damaged later results in reduction in the mother's blood supply. Your lifestyle can also damage the placenta. For example if pregnant mothers smoke or take some kinds of illegal drugs. Placental insufficiency (also called placental dysfunction or uteroplacental vascular insufficiency) is an uncommon but serious complication of pregnancy. It occurs when the placenta does not develop properly, or is damaged. This blood flow disorder is marked by a reduction in the mother's blood supply. Your lifestyle can also damage the placenta. Placental insufficiency can occur if you smoke or take some kinds of illegal drugs while you're pregnant. Medical conditions such as diabetes, pre-eclampsia and blood clotting conditions also increase your risk [23]. Once the uteroplacental vascular insufficiency sets in due to what so ever reasons may be it cannot be cured. It's extremely important to rece The earlier belief that infection from mother to fetus does not pass through placenta, however, recent researches has shown that some kind of infection can pass across the barrier. live an early diagnosis and adequate prenatal care. These can improve the baby's chances of normal growth and decrease the risk of birth complications [25].

The earlier belief that infection from mother to fetus does not pass through placenta, however, recent researches has shown that some kind of infection can pass across the barrier. Recent studies have suggested that measuring placental hormones such as sEng, sFlt-1 and PlGF may help to identify women at increased risk of foetal growth restriction and preeclampsia. $(25,26)$

\section{Placental-Covid-19 Immunopathology}

Human third trimester placentas showed SARS-CoV-2 infection in placental histopathology sections [20].The possible infectivity may be due to the transplacental transmission of SARS-CoV-2 infection is possible during the last weeks of pregnancy. After the entry of the virus through the eyes, nose, or mouth during secondary viremia because of transplacental transmission may cause placental inflammation and neonatal viremia [27-30].Two infants had In Corona infected pregnant mothers, it is shown that concentration of $\operatorname{IgG}$ and $\operatorname{IgM}$ antibodies are higher in the fetus. Their mothers also had elevated levels of IgG and IgM Three infants had elevated IgG levels but normal IgM levels; all 3 mothers had elevated $\operatorname{IgG}$ and 2 also had elevated IgM levels. Inflammatory cytokine IL-6 was significantly increased in all infants, however according to the authors none of the infants presented any symptoms as of March 8, 2020 [29].

\section{References}

1. Gupta PD (2019) Modulation of Human Placental Role: Revisited Int J cell Sci \& mol biol 6 (4) 106-107

2. Sterpu I, Fransson E, Hugerth LW. (2020) No evidence for a placental microbiome in human pregnancies at term. Am J Obstet Gynecol; In Press, Corrected Proofhttps://doi.org/10.1016/j.ajog.2020.08.103 
3. Aagaard, K. et al. 2014. The placenta harbors a unique microbiome. Sci. Transl. Med. 6, 237ra65 .

4. Stinson L F. et al. (2019) The Not-so-Sterile Womb: Evidence That the Human Fetus Is Exposed to Bacteria Prior to Birth. Front. Microbiol., 04 June 2019

5. Stout, M. J. et al. (2013) Identification of intracellular bacteria in the basal plate of the human placenta in term and preterm gestations. Am. J. Obstet. Gynecol. 208, 1-7.

6. Kumar H, Lund R, Laiho A, Lundelin K, Ley RE, et al. (2014) Gut Microbiota as an Epigenetic Regulator: Pilot Study Based on Whole-Genome Methylation Analysis. mBio 5(6): e2113-14.

7. Young V B (2017)The role of the microbiome in human health and disease: an introduction for clinicians BMJ ;356:j831

8. Rubella (German measles) in pregnancy. (2007). Paediatrics \& child health, 12(9), 798-802.

9. James H Kim , Anthony and R Scialli 2011 Thalidomide: the tragedy of birth defects and the effective treatment of disease. Toxicol Sci 122(1):1-6.

10. Gupta, P D. (2020). It Matters, How Your Mother was Born?. Genom \& Gene Ther Int, 4(1): 000118.

11. Wampach L, Heintz Buschart A, et al. (2018). Birth mode is associated with earliest strain-conferred gut microbiome functions and immune stimulatory potential. Nature Communications 9: 5091.

12. Jiménez, E. et al. (2005). Isolation of commensal bacteria from umbilical cord of healthy neonates born by caesarean section. Curr. Microbiol. 51, 270-274

13. Gupta P D, and Tyagi S (2020).. Development of immune system from new born to adult: a new insight. J Cell Tissue Res 20(1): 6853-6860.

14. Stephanie E. Ander Michael S. Diamond and Carolyn B. Coyne(20019).Immune responses at the maternal-fetal interface Science Immunology 4, (31), eaat6114

15. McGovern, N., Shin, A., Low, G. et al. (2017). Human fetal dendritic cells promote prenatal T-cell immune suppression through arginase-2. Nature 546, 662-666

16. Naomi McGovern, Amanda Shin , Gillian Low (2017). Human fetal dendritic cells promote prenatal T-cell Nature.;546(7660):662-666
17. Mold J E, Michaëlsson Jakob, et al. (2008). Maternal alloantigens promote the development of tolerogenic fetal regulatory $\mathrm{T}$ cells in utero Science322(5907)1562-1565

18. Ramdev Konijeti Jacob Rajfer and Asghar Askari(2009)., Placenta Percreta and the Urologist Rev Urol. 11(3): 173-176.

19. Jing L, Wei G, Mengfan S \& Yanyan H. (2018). Effect of site of placentation on pregnancy outcomes in patients with placenta previa. PLoS ONE , 13, e0200252.

20. Graham J Burton Christopher W Redman et al. (2019). Preeclampsia: pathophysiology and clinical implications BMJ ;366:12381

21. Oyelese Y \& Smulian JC. (2006). Placenta previa, placenta accreta, and vasa previa. Obstet Gynecol , 107, 927-41. PMID: 16582134 DOI.

22. Ahmed A \& Gilbert-Barness E. (2003). Placenta membranacea: a developmental anomaly with diverse clinical presentation.Pediatr. Dev. Pathol. , 6, 201-2

23. Ahmet Alexander Baschat 2004 Fetal responses to placental insufficiency: an update BJOG 111,(10) 1031-104

24. Colin P Sibley 2017 Treating the dysfunctional placenta J Endocrinol. 234(2): R81-R97.

25. Heerema-McKenney A. (2018). Defense and infection of the human placenta. APMIS , 126, 570-588

26. Sharon E. Maynard, MD* and S. Ananth Karumanchi, Angiogenic Factors and Preeclampsia Semin Nephrol. 2011 Jan; 31(1): 33-46.

27. Sharps M C , Dexter J et al (2020). A structured review of placental morphology and histopathological lesions associated with SARS-CoV-2 infection Placenta. 101:13-29

28. Gupta P D 2020 Cytokines: the Game Changer in Pathogenesis of Covid-19. J Clin Exp Immunol, 5( 6) $\mid 2832020$

29. Zeng H, Xu C, Fan J, et al. . (2020) Antibodies in Infants Born to Mothers With COVID-19 Pnumonia. JAMA; 323(18):18481849.

30. Vivanti, A.J., Vauloup-Fellous, C., Prevot, S. et al. (2020). Transplacental transmission of SARS-CoV-2 infection. Nat Commun 11, 3572

31. Prochaska E Jang M, Burd I (2020). COVID-19 in pregnancy: Placental and neonatal involvement Am J Reprod. Immunol. 84, (5) :e13306
This work is licensed under Creative Commons Attribution 4.0 License

\section{To Submit Your Article Click Here: Submit Manuscript}

DOI: $10.31579 / 2578-8965 / 060$

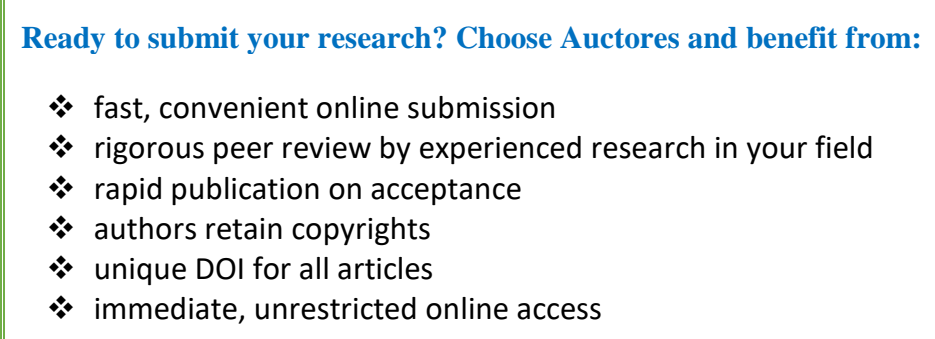

At Auctores, research is always in progress.

Learn more www.auctoresonline.org/journals/obstetrics-gynecology-andreproductive-sciences 